\title{
Disputas en torno a las políticas públicas, la legislación laboral y el bienestar obrero en la industria azucarera de Tucumán/Argentina $(1917-1943)^{*}$
}

María Fernández de Ullivarrí

\begin{abstract}
Afiliada institucionalmente al Consejo Nacional de Investigaciones Científicas y Técnicas-CONICET (Argentina). Correo electrónico: ulliva@gmail.com. La autora es doctora en Historia de la Universidad de Buenos Aires (Argentina). Entre sus publciaciones recientes tenemos: "La política en el mundo obrero en el Tucumán de entreguerras" Revista Izquierdas No. 31 (2016) y "Demandas de asistencia médica en los territorios azucareros. Tucumán en tiempos de entreguerras", Revista Varia Historia, Belo Horizonte, Vol. 32 No. 60 (2016). Entre sus temas de interés están Historia social del trabajo, historia social del boxeo.
\end{abstract}

Recibido: 30 de agosto de 2016

Aprobado: 1 de noviembre de 2016

Modificado: 2 de enero de 2017

Artículo de investigación científica

DOI: http://dx.doi.org/10.15648/hc.31.2017.9

* $\quad$ Este artículo forma parte del proyecto: "Cultura y política en el mundo del trabajo tucumano en los años de entreguerras" financiado por el Consejo Nacional de Investigaciones Científicas y Técnicas (Argentina).

Esta publicación está bajo una licencia Creative Commons Reconocimiento-NoComercial 4.0 
Disputas en torno a las políticas públicas, la legislación laboral y el bienestar obrero en la industria azucarera de Tucumán/Argentina (1917-1943)

\title{
Resumen
}

El objetivo es analizar las disputas entre el Estado tucumano y los empresarios del azúcar, por la implementación de políticas sociales y la reglamentación de leyes obreras en la industria azucarera. Interesa, a partir de allí, pensar las tensiones, las posibilidades y los límites para concretar políticas públicas orientadas al bienestar del mundo rural de una provincia argentina. Se aborda esta problemática en el marco de las discusiones sobre el bienestar obrero (y la apropiación de su sentido) que se produjeron en la provincia durante el período de gobierno de la Unión Cívica Radical (1917-1943).

Palabras clave: Tucumán, industria azucarera, bienestar, política.

Disputes around public policies, Labour Legislation and Workers Welfare in the sugar industry of Tucumán-Argentina (1917-1943)

\begin{abstract}
The purpose is to analyze disputes between Tucumán State and sugar entrepreneurs, due to the implementation of social policies and labor laws regulations in the sugar industry. From this point, it is important to think the tensions, the possibilities and the limits in order to establish public policies aimed at well-being of the rural world of an Argentine Province. This problem is focused on the discussions about Labour Welfare (and the appropriation of its purpose) that occurred in the province during the period of the Radical Civic Union government (1917-1943).
\end{abstract}

Keywords: Tucumán, sugar industry, welfare, politics.

Disputas em torno ás políticas públicas, a legislação trabalhista e o bem estar operário na indústria açucareira de Tucumán-Argentina (1917-1943)

\section{Resumo}

O objetivo é analisar as disputas entre o Estado tucumano e os empresários do açúcar, pela implementação de políticas sociais e a regulamentação de leis operárias na indústria açucareira. Interessa, a partir de aí, pensar nas tensões, as possibilidades e os limites para concretar políticas públicas orientadas ao bem-estar do mundo rural de uma província 
argentina. Aborda-se esta problemática no marco das discussões sobre o bem-estar operário (e a apropriação de seu sentido) que se produziram na província durante o período de governo da União Cívica Radical (1917-1943)

Palavras-chaves: Tucumán, indústria açucareira, bem estar, política

Lutte autour des politiques publiques, la législation du travail et le bien-être des ouvriers dans l'industrie sucrière de Tucumán/Argentina (1917-1943)

\section{Résumé}

L'objectif est celui d'analyser les luttes entre l'Etat tucumano et les chefs d'entreprise du sucre, dû à la mise en œuvre de politiques sociales ainsi qu’à la réglementation des lois ouvrières dans l'industrie sucrière. Il est important, à partir de là, de penser aux tensions, aux possibilités et aux limites pour concrétiser des politiques publiques orientées vers le bien-être du monde rural d'une province argentine. Cette problématique est abordée dans le cadre des discussions sur le bien-être ouvrier (et l'appropriation de son sens) qui se sont déroulées dans la province pendant la période du gouvernement de l'Union Cívica Radical (1917-1943).

Mots clés: Tucumán, industrie sucrière, bien-être, politique.

\section{INTRODUCCIÓN}

A mediados de 1937 el senador socialista Alfredo Palacios abandonó la provincia de Tucumán luego de una larga gira. El fin era recoger datos sobre las condiciones de vida de la población rural, para elaborar un proyecto de ley de protección de niños en edad escolar. Parte de esas impresiones quedaron reflejadas en el libro El Dolor argentino. Allí decía: "Mucho está realizando la acción oficial, procurando enderezar la curva de destinos que tan tristes se prevén, mediante sucesivas obras de asistencia social, como hospitales regionales, estaciones sanitarias, gotas de leche, colonias, asilos de menores, colonias de vacaciones para niños débiles, hogares para huérfanas, dispensarios antipalúdicos y otras realizaciones de aliento. Pero poco a nada vale que el Estado se inquiete por mejorar la afrentosa situación de esta gente, ya que choca con la indiferencia obstruccionista del 


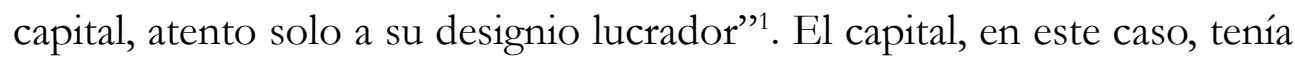
nombre de industria azucarera y estas declaraciones resumían una parte central de la dinámica política de la provincia y describían las mayores dificultades que existían para discutir e implementar en el mundo rural, las políticas de protección social que en los espacios urbanos comenzaban a tomar forma ${ }^{2}$.

Ubicada a más de 1200 kilómetros de Buenos Aires, la agroindustria azucarera de la provincia de Tucumán no solo era una actividad económica, sino un complejo entramado social, político y cultural que digitaba los ritmos de la provincia. Como rueda nodal del desarrollo local, la actividad tenía acuerdos establecidos con gran parte de los sectores políticos y también los económicos de la región y de la Nación. Al calor de esos pactos había crecido, y en muchas ocasiones este conjunto de relaciones le permitió a los empresarios sostener espacios laborales poco permeables a las legislaciones vigentes y amurallarse frente al avance de la legislación social que comenzaba a ampliarse en el país.

No obstante, el ascenso de la Unión Cívica Radical (UCR) al poder (nacional y provincial) luego de la reforma electoral de 1912, que garantizó el voto universal (masculino), secreto y obligatorio, imprimió una nueva tónica al vínculo entre el gobierno y la industria azucarera de la provincia. Uno de esos cambios se visibilizó en los esfuerzos que, en mayor o menor medida, hicieron los gobiernos para modificar las relaciones laborales a través de la legislación protectora y delimitando las fronteras del Estado al interior de los fundos azucareros. El proceso de consolidación de una agenda de bienestar tuvo, en el área azucarera, que involucrar tanto los espacios laborales como los espacios de reproducción que se encontraban profundamente yuxtapuestos. Pero era muy difícil convencer a un sector

1 Alfredo Palacios, El dolor argentino (Buenos Aires: Claridad, 1938), 88-89.

2 Laura Golbert, "Notas sobre la situación de la historiografía sobre la política social en Argentina", en El país del no me acuerdo. (Des)memoria institucional e historia de la política social en la Argentina, comp por Julián Bertranou, Juan Manuel Palacio, y Gerardo Serrano (Buenos Aires: Prometeo, 2004), 25-32; Karina Ramacciotti y Carolina Biernat, Las políticas sociales en Argentina: entre demandas y resistencias (Buenos Aires: Biblos, 2012); Daniel Lvovich y Juan Suriano (editores), Las políticas sociales en perspectiva histórica (Buenos Aires: Prometeo, 2006). 
del mundo rural tucumano, principal proveedor de recursos al Estado, de la necesidad de articularse con políticas sociales que comenzaban a tomar forma en el mundo urbano. En parte porque la industria azucarera modeló las estructuras económicas de las regiones donde se implantó e incidió sobre las configuraciones del poder. En esa dinámica, conformó espacios con pretensiones de autonomía frente al Estado y la legislación, articulando su defensa en la importancia del sector agroindustrial para el desarrollo económico y social de la provincia e imponiendo una suerte de "consenso azucarero" tendiente a sostener el statu quo. Frente a eso, los esfuerzos por transformar el mundo rural de la provincia involucraron mucho más que una disputa por la legitimidad estatal y los recursos, fue también un eje nodal de una lucha política y simbólica entre gobierno e industria, que atravesó todo el período de entreguerras en Tucumán. Por eso el proceso estuvo poblado de tensiones y allí los trabajadores aprovecharon para insertar también sus demandas y, especialmente, trabajar sobre espacios de organización gremial que les permitieran convertirse en actores capaces de disputar los términos en los cuales los recursos de la industria eran redistribuidos.

En este escenario, nuestro objetivo es analizar las discusiones sobre el bienestar que sostenían el Estado y los empresarios, para pensar las posibilidades y los límites para concretar políticas públicas orientadas al mundo rural y vinculadas al empleo. Nos paramos entonces en la pregunta por las tensiones entre las fuerzas sociales involucradas, las ideas circulantes y los medios políticos utilizados para poner en agenda la cuestión social y resolver algunas demandas obreras en la provincia. Así, nos proponemos analizar las negociaciones, las acciones y las dificultades de un estado provincial para disputar políticamente con el poder económico local y forjar un escenario de derechos laborales sobre espacios poco dispuestos a ceder beneficios. Partimos de suponer que las configuraciones políticas y económicas de los estados provinciales configuraron las lógicas y las formas de las políticas sociales, pero las posibilidades estuvieron vinculadas a las disputas por el poder entre y dentro de los agentes involucrados.

Las fuentes utilizadas en el trabajo son la prensa comercial y obrera tanto nacional como provincial, revistas empresarias, estadísticas de la Dirección 
de Estadísticas de la Provincia, Archivo de la Legislatura de la provincia de Tucumán y debates legislativos.

\section{LA INDUSTRIA AZUCARERA TUCUMANA}

Esta industria era un gran complejo agroindustrial compuesto por 27 ingenios y más de quince mil plantaciones cañeras. Una de las características particulares de la estructura agraria de la provincia era la subdivisión de la tierra, donde convivían latifundios y minifundios en consonancia con diferentes modos de tenencia: aparceros, colonos, arrendatarios, propietarios pequeños y grandes ${ }^{3}$. Esta característica fue nuclear en el desarrollo de las disputas en torno al uso de la tierra y el agua, pero también la fragmentación imprimió su sello sobre el mercado de trabajo ${ }^{4}$. Por la cantidad de mano de obra que requería la zafra azucarera la industria implementó desde sus inicios y con apoyo estatal, medidas coercitivas para retener y disciplinar a los trabajadores. Docilidad, baratura y productividad eran los atributos deseados y las técnicas para lograrlo eran "azote, salario y ley" La mano de obra era un problema nodal de la actividad, ya que a pesar de las innovaciones tecnológicas que caracterizaron el avance de esta rama de actividad, hasta la década de 1960 la cosecha siguió realizándose con

3 Las colonias eran parcelas de tierra cedidas por el ingenio para ser trabajadas por otros. La empresa cedía el fundo a un productor y aportaba instrumentos de labranza y lo necesario para el cultivo y cosecha a cambio de un porcentaje en el precio de la caña, que a diferencia de los cañeros se convenía sobre la riqueza sacarina, no sobre su peso. Los cañeros independientes, por su parte, trabajaban sus tierras y vendían al ingenio caña por peso. Mientras que los arrendatarios pagaban un canon y además tenían condiciones especiales fijadas por la empresa, muchas de las cuales eran servicios en el fundo del ingenio. Augusto Bravo, La industria azucarera en Tucumán. Sus problemas sociales y sanitarios (Tucumán: Imprenta Violetto, 1966), 58.

4 Daniel Campi, “Azúcar y trabajo. Coacción y mercado laboral en la Argentina, 1856-1896”, (Tesis de Doctorado, Universidad Complutense de Madrid, 2002): 78.

5 Daniel Campi y Patricia Juárez Dape, "Despegue y auge azucarero en Perú y Argentina: semejanzas y contrastes”, Illei i Imperi, 9, (2006): 100. En la mayoría de las zafras la población nativa no era suficiente, de manera que los ingenios y fincas recurrían a mano de obra proveniente de provincias vecinas. Los recelos en cuanto a la provisión de mano de obra en una actividad con uso intensivo, pero temporal, del factor trabajo implicaron que en muchas oportunidades la competencia por los trabajadores fuera cruenta y que, en muchas otras, aquellos interesados en mantener el status quo productivo pusieran trabas a los intentos estatales de diversificar la producción en la provincia, sobre todo la industrial. 
utilización masiva de trabajo humano. ${ }^{6}$ Por eso, gran parte del mercado laboral tucumano estaba regido por los intereses del azúcar a través de sus corporaciones.

Alrededor del azúcar se configuró gran parte del entramado productivo local, donde el campo y la ciudad capital estaban fuertemente entrelazados. La mayoría de los trabajadores rurales estaban vinculados de una u otra manera a la industria madre, mientras que muchos obreros urbanos trabajaban en industrias proveedoras, como la metalúrgica ${ }^{7}$. Por lo general aquellos que trabajaban permanentemente en las fábricas azucareras contaban con algunos beneficios. El resto, -obreros del surco, quinteros, "trabajadores golondrina", etc.- vivían en condiciones bastante más precarias $^{8}$.

La característica general del espacio de producción era el ingenio. Ordenado como una fábrica-villa, la empresa ejercía el control directo de la fuerza de trabajo a través de todas las esferas de la vida de los trabajadores, con el fin de sostener valores relacionados con la disciplina laboral, la austeridad y la religiosidad ${ }^{9}$. En el territorio del ingenio casi todo era propiedad de la empresa, incluyendo las viviendas. Sus habitantes y los que llegaban para la

6 Sobre los avances tecnológicos en la industria véase Daniel Moyano, Desde la empresa (Buenos Aires: Prometeo, 2015).

7 Daniel Moyano, "Empresas azucareras, tecnología y actividad metalúrgica en Tucumán en la primera mitad del siglo XX", Actas de las II Jornadas de Jóvenes Investigadores, UNT-AUGM, Vol. No, (2008).

8 Algunas crónicas de la época dan cuenta de ello cuando relatan que en esos fundos "Las casas son de material, en el mejor de los casos, cuando no miserables ranchos de quincha que no abrigan en invierno y cuyo techo de zinc irradia una temperatura insoportable en verano". Miguel Figueroa Román, "Problemas sociales de Tucumán", Revista Sustancia, enero-febrero, año IV, No. 13. Tucumán, (1943) 151. El mundo del trabajo en el ingenio se transformaba con la zafra. En mayo-junio, comenzaban a llegar a los predios y a las colonias miles de trabajadores, muchos de los cuales venían de las provincias vecinas. Las caravanas se componían de familias enteras, porque mujeres y niños colaboraban en el trabajo a destajo en el surco, donde se pagaba por tonelada de caña hachada y pelada. Los trabajadores estacionales solían ubicarse en alojamientos miserables, la mayoría de los cuales eran casas colectivas o una suerte de galpón donde vivían entre ocho o diez familias.

9 José Sergio Leite Lópes, El Vapor del Diablo. El trabajo de los obreros del azúcar, (Buenos Aires: Antropofagia, 2011); Josefina Centurión, Cultura y Sociabilidad en los Pueblos Azucareros" (Tesina de Licenciatura, Universidad Nacional de Tucumán, 2000), 15; Lucía Santos Lepera, "La Acción Católica Tucumana, sociabilidad y cultura religiosa en los años treinta. El caso del Centro de Hombres de San Pablo", mimeo, (2008): 3. Daniel Campi, "Contrastes cotidianos. Los ingenios del norte argentino como complejos socioculturales, 1870-1930”, Varia Historia, vol. 25, N 41 jan/jun (2009): 245-267. 
zafra, debían adaptarse a la organización del tiempo y la disciplina laboral impuesta por la fábrica ${ }^{10}$.

Dentro del pueblo, la distribución del espacio reflejaba el mundo de las jerarquías sociales y económicas que caracterizaron a la industria. En un territorio acotado vivían patrones, personal jerárquico y de dirección, técnicos y empleados administrativos, obreros calificados y peones temporarios y permanentes ${ }^{11}$. Apartados del pueblo, en las colonias y campos, habitaban los zafreros y sus familias. De esta heterogeneidad, donde las brechas eran muy marcadas, dan cuenta las memorias infantiles de José Carmona, un obrero de ingenio e hijo de un peón de surco, quien relata: "En el Santa Ana algunos obreros de fábrica tenían auto [...] Cuando íbamos a la escuela los hijos de los obreros de fábrica nos despreciaban y nos decían: ahí vienen los empeñaos, y no se juntaban con nosotros" ${ }^{\prime 2}$.

La escala de salarios era amplia, pero en su mayoría, especialmente los del campo, eran magros y no alcanzaban para cubrir la subsistencia. Alfredo Palacios comentaba en el Senado Nacional que estos trabajadores por lo general "no alcanzan a ganar dos pesos. El resto del año viven por obra de la providencia". ${ }^{13}$ Esto solía agravarse más, porque los alimentos debían comprarse en las proveedurías de ingenio, con precios mucho mayores que los del comercio de la zona. Y muchas veces esas compras eran compulsivas. En ese sentido, las denuncias obreras de que los obligaban: “(a) sacar las mercaderías pagando dos veces lo que valen, porque si no nos hechan (sic)" eran frecuentes ${ }^{14}$.

Estructurado a través de un sistema coercitivo organizado en torno a los capataces y mayordomos, contando además con ayuda de la policía, un sistema de control procuraba disciplinar a los trabajadores, disminuir el au-

10 Daniel Campi, Contrastes cotidianos, 245-267.

11 El pueblo generalmente se dividía en dos partes. Una de ellas estaba abocada a las viviendas de empleados jerárquicos, mientras que en otro sector vivían los peones y trabajadores permanentes.

26612 Entrevista al Sr. José Florentino Carmona, obrero del ingenio Santa Ana, realizada por Josefina Centurión Ciudad, marzo de 2000.

13 Diario de Sesiones de la Cámara de Senadores de la Nación Junio 22 de 1937, 199.

14 “Carta firmada por Obreros del Ingenio San Juan”, El Orden, 29/04/1931. Paréntesis en el original. 
sentismo, el alcoholismo y potenciar la productividad del trabajo ${ }^{15}$. Por eso existía dentro de los territorios azucareros una intensa vigilancia. "Controlan la entrada de todos los que van a trabajar a la fábrica para evitar la intromisión de algún agitador que pueda, levantando el espíritu de los serviles a sus órdenes, perturbar la tranquilidad del señor de horca y cuchillo"16, relataba el diario anarquista Tierra Libre.

Históricamente las empresas habían procurado eliminar los impulsos refractarios de los trabajadores y lograban no solo que la gente obedeciera a través del poder de policía y el manejo de las relaciones laborales como una cuestión de orden público, sino también porque la consolidación de una hegemonía cultural en el mundo azucarero, volvía esas realidades un paisaje cotidiano Los procesos de dominación arraigaban en las esferas más profundas de los y las trabajadoras ${ }^{17}$. Sin embargo, también era cierto que la jornada de trabajo de doce horas, las proveedurías, el pago con vales, los malos tratos, las irregularidades en el pesaje de la caña, etc., implicaban la anuencia o por lo menos la indiferencia del Estado. En esa dirección, los esfuerzos por transformar algunas de estas prácticas fueron convirtiendo la agenda política y social tucumana en una disputa (con negociación) entre gobierno e industria y sobre ello nos detendremos a continuación.

\section{GOBIERNO E INDUSTRIA. LOS PRIMEROS CONFLICTOS}

La consolidación de la actividad azucarera en el campo tucumano fue el resultado de una alianza entre élites y poder político que posibilitó las condiciones de desarrollo y de sustentabilidad del sector ${ }^{18}$. Como consecuencia de ello, desde su conformación, el éxito del modelo de producción

15 Daniel Campi y Rodolfo Richard Jorba "Un ejercicio de historia regional comparada: coacción y mercado de trabajo.Tucumán y Mendoza en el horizonte latinoamericano (segunda mitad del siglo XIX)” História Econômica \& História de Empresas, [S.I.], v. 4, n. 2, (2012): 97-130.

16 Tierra Libre, junio de 1932.

17 Charles Hale, Resistance and Contradiction Miskity Indians and the Nicaraguan State, 1894-1987 (California:Stanford University Press, 1994); James Scott, Los dominados y el arte de la resistencia. Discursos ocultos (México: Era, 2000); Adrián Ascolani, El sindicalismo rural argentino (Bernal: EdUNQui, 2009).

18 Noemí Girbal-Blacha, "Azúcar, Poder Político y Propuestas de Concertación para el Noroeste argentino en los años 20. Las conferencias de gobernadores de 1926-1927”, Desarrollo Económico Vol. $34, \mathrm{~N}^{\circ} 133$ (1994): 107-122. 
estuvo vinculado al Estado y los industriales, agrupados en corporaciones con base en Buenos Aires y en Tucumán, estaban familiarizados con la intervención estatal ${ }^{19}$. Al Estado -provincial y nacional- habían recurrido desde sus inicios para obtener un cuerpo legal y aranceles aduaneros que permitieran su despegue, consolidación y funcionamiento. Estos vínculos garantizaban condiciones de producción seguras y una política arancelaria favorable, que era decisiva para la supervivencia de la actividad.

Sin embargo, a partir de la democratización introducida por la reforma electoral de 1912, la multiplicación de nuevas demandas, especialmente de aquellas con representación corporativa, comenzó a hacer más dificultosa (y ciertamente menos jugosa) la distribución de los beneficios de la industria ${ }^{20}$. El triunfo electoral de la Unión Cívica Radical en el país y en la provincia cambió la forma de hacer política y también la mirada sobre la industria azucarera. El nuevo gobierno nacional no estaba interesado en sostener el sistema de alianzas previo a 1912, que había asegurado la protección azucarera a cualquier costo. Estos gestos avalaron los intentos del radicalismo tucumano para avanzar sobre los enclaves azucareros y profundizar la puja por los recursos entre industria y Estado, intentando anclar el enfrentamiento político en un marco de regulación de leyes de carácter social. Así, los gobiernos radicales se caracterizaron por intentar, con diferente grado de éxito, transformar la noción de asistencia social que garantizaba la provisión de ciertos beneficios sociales con tinte de merced, y que regía en los espacios azucareros, para convertirla en una práctica obligatoria y garantizada por ley ${ }^{21}$.

En ese escenario, el Estado se configuró como un nuevo territorio para arbitrar el prorrateo de beneficios en una nueva clave que incluía la legislación social. Estos esfuerzos se vieron reforzados luego de un laudo

19 José Antonio Sánchez Román, "La dulce crisis. Finanzas, Estado e Industria Azucarera en Tucumán, Argentina (1853-1914)" (Tesis de Doctorado, Universidad Complutense de Madrid, 2001).

20 Tulio Halperin Donghi, Vida y muerte de la República Verdadera (1910-1930) (Buenos Aires: Ariel, 2000).

21 Sobre la idea de asistencia en los ingenios véase; Alejandra Landaburu, "Los empresarios azucareros y la cuestión social. Tucumán 1916-1930” (Tesis de Doctorado, Universidad Nacional de Tucumán, Tucumán, 2014): 12 
arbitral del presidente en 1928 que dejó sentado el criterio de protección distributiva. Este arbitraje presidencial fue el resultado de un violento conflicto entre cañeros e industriales por el precio de la materia prima. En el fallo, el árbitro señaló que el desarrollo de la industria, por sus "características propias [...] se ha efectuado al amparo de leyes nacionales protectoras" ${ }^{22}$. Y, a tono con el discurso de los cañeros, destacó que los dueños de los ingenios "desconocen que si el público argentino protege a una industria es para estimular el desenvolvimiento material de muchos millares de conciudadanos y no para aventajar a unos pocos capitalistas"23. Así, "la única premisa que invoca el proteccionismo, en la doctrina y en la práctica, es la obtención derivada de un precio equitativo permanente para los productores y un lógico bienestar para los que trabajan" ${ }^{24}$. De esta forma, el presidente reformulaba la noción de proteccionismo aduanero, dejando claro en el laudo que el Estado debía asegurar la distribución de beneficios para todos los actores involucrados en la industria.

Finalmente, en esta sentencia, Alvear se aseguró bien de separar la noción de bienestar de la de la mera subsistencia y ese guante fue recogido por el gobierno provincial ${ }^{25}$. Pero convencer al mundo rural de cuestiones que comenzaban a ser aceptadas en los mundos urbanos tenía sus complejidades. Por falta de fuerza imperativa, voluntad política, consenso legislativo y organismos de control sólidos, la aplicación de leyes laborales quedó sujeta a la buena voluntad de los empresarios ${ }^{26}$. La estrategia industrial, por otro lado, fue muy prolija. Así, aunque enfrentados internamente, cerraron filas en torno a una retórica que remarcaba la inviabilidad de las mejoras socia-

22 Laudo Alvear, Biblioteca del Congreso de la Nación, Serie 7, Asuntos Económicos (Buenos Aires, 1965), 7.

23 Laudo Alvear,Biblioteca del Congreso 9. Las campañas contra la protección de las "industrias parasitarias" eran muy fuertes y constituían a la opinión pública en un factor más en la trama de intereses cuando se debatían políticas azucareras. Al mismo tiempo, las condiciones de vida y trabajo de los obreros estaban constantemente en el centro del debate político.

24 Laudo Alvear, Biblioteca del Congreso 9.

25 Laudo Alvear, Biblioteca del Congreso 11.

26 Diez años después de 1928 todavía se seguía reclamando el pago de lo acordado. En 1933 los socialistas denunciaron que en la zafra del año anterior se había pagado $\$ 2,20$ por tonelada y que ese año se pagarían solo \$2. (Diario de Sesiones de la Honorable Legislatura de la Provincia de Tucumán, año 1933, 776-792). Por otro lado, a fines de los años treinta se destacó que algunos ingenios aún pagaban con vales o con melaza. 
les y el rechazo del avance del Estado y la legislación de protección social que comenzaba a afianzarse en la Argentina de las entreguerras. Ante cada conflicto argumentaban que la elevación de los costos de producción perjudicaría al sector. Fundamentalmente porque la demanda inelástica del consumo de azúcar dificultaba cualquier estrategia de aumentar ventas, mientras que por otro lado, los precios estaban regulados por el gobierno y la industria no podía fijar tarifas. Asimismo, diseñaron una defensa sostenida sobre los beneficios sociales que la actividad generaba para los trabajadores y lo hicieron a través de un continuo lobby que, elaborado en clave de progreso, construía a la actividad azucarera como indispensable para el desarrollo de la región ${ }^{27}$. Así, utilizaban a modo de propaganda el rol social de la industria en la provincia, la cual -aducían- proporcionaba medios de vida permanente y bienestar a muchos hombres y mujeres por quienes decían preocuparse genuinamente ${ }^{28}$.

El discurso industrial oficial, publicado mayormente en la Revista Azucare$r a$, su revista corporativa, destacaba que "en numerosos ingenios existían hospitales, escuelas y otras instituciones de beneficencia" con la idea de revelar "su interés personal por la suerte de sus obreros". Así, sin temor a equivocarse, aseguraban que "el obrero de un ingenio sabe que no queda abandonado cuando se enferme, como sucede a sus compañeros de otros establecimientos industriales" ${ }^{\prime 2}$. Por su parte, su vocero, el periodista Emilio Schleh, aseguraba que los trabajadores de fábrica eran beneficiarios de "vivienda higiénica de material, de servicio médico y provisión de medicinas gratis, de enseñanza pagada por los ingenios [...] socorros a los enfermos y seguros por accidentes del trabajo." 30 .

A través de la noción de "buen patrón", los azucareros ocultaban una concepción de las relaciones laborales circunscriptas al ámbito de lo pri-

27 María Lenis, "La política editorial del Centro Azucarero Argentino, 1894-1923”. En Actas del III Seminario de Historiado Acucar Sao Paulo:usp, 2010 (Ver pág. 25)

28 María Lenis, "Empresarios azucareros y cuestión social. El Centro Azucarero Argentino frente a las huelgas de 1923 en Actas de las VIII Jornadas La Generación del Centenario y su proyección en el NOA, 1900-1950", Tucumán: Editorial, (2009): 5.

29 Revista Azucarera, diciembre de 1913, 243.

30 Emilio Schleh, La industria azucarera en su primer centenario. (Buenos Aires: Ferrari Hnos, 1921), 271. 
vado, donde tanto estas, como las condiciones en las que el trabajo se desarrollaba no eran establecidas y reguladas por las agencias estatales, sino que eran definidas por los criterios de los empleadores. Por ello, todas las atenciones y beneficios sociales se aceptaban solo como concesiones y no como parte de una legislación de cumplimiento forzado ${ }^{31}$. Cualquier intento de encontrar una solución a los problemas obreros y garantizarles un mayor grado de bienestar implicaba un proceso intenso de negociación y finalmente debía lidiar con la resistencia de los empresarios. En definitiva, intervenir en el mundo azucarero movía todo un complejo engranaje económico y político que daba forma a la trama institucional tucumana.

Una de las primeras medidas de intervención estatal en ámbitos azucareros fue la creación del Departamento Provincial del Trabajo (DPT), mediante un decreto del gobernador Juan Bascary en $1917^{32}$. Su intención era tener una herramienta de inspección y control que pudiera insertarse en los espacios cerrados de los ingenios. Sin embargo, esta repartición estatal se convirtió en el blanco de las críticas, porque decían los voceros de la actividad azucarera, hacía "cuestión de gobierno, de tiranía, de lo que es una cuestión particular, privada y librada a lo que las partes convengan"33. Aferrados al carácter privado de las relaciones laborales, los industriales y plantadores estaban dispuestos a resistir los intentos del gobierno por regularlas.

Intentaron frenar, con más éxitos que fracasos, a partir del lobby y los contactos en la legislatura, todos los proyectos presentados: las medidas de control sobre la educación de los menores que trabajaban en los ingenios, la creación de "villas obreras", los proyectos de asistencia médica, el pago en moneda nacional, la jornada de trabajo de 8 horas y un proyecto de Cámara de Trabajo con inspección obrera de los lugares de trabajo ${ }^{34}$. Pero

31 Alejandra Landaburu, "Los empresarios azucareros y la cuestión social. Tucumán 1916-1930” (Tesis de Doctorado,Universidad Nacional de Tucumán, Tucumán, 2014): 10.

32 Alejandra Landaburu, Los empresarios; Alejandra Landaburu, "Los industriales y el Departamento Provincial del Trabajo ante el conflicto obrero de 1919 en Tucumán”, en La Sociedad del trabajo, comp. Mirta Lobato y Juan Suriano (Buenos Aires: Edhasa, 2014), 89.

33 El Orden, 05/07/1919; El Orden, 09/08/1919.

34 Diario de Sesiones de la Cámara de Diputados de Tucumán. Período legislativo de 1918-1919, 91-95; Alejandra Landaburu, Los empresarios, 131. 
lo que no pudieron frenar fue la política azucarera del presidente Yrigoyen,-que incluyó importación de azúcar-, que había comenzado a generar incomodidades incluso dentro del propio radicalismo local ${ }^{35}$.

Esas tensiones internas se fueron profundizando y en las elecciones de 1922 logró imponerse un ala del radicalismo enfrentada al yrigoyenismo. Octaviano Vera llegó al poder con el apoyo industrial que, no obstante, duró muy poco. El tono plebeyo con el que el verismo asumió el gobierno marcó la nota de la gestión, así como también la profunda retórica de "reparación social" que continuaba a la del gobierno anterior ${ }^{36}$. Apenas asumió Vera propuso dar nueva forma institucional al DPT, extendiendo la presencia del Estado en los conflictos laborales, especialmente en el mundo rural. También pensó poner fin a las proveedurías de los ingenios y cambiarlas por cooperativas de consumo. Asimismo, comenzó a evaluar la posibilidad de armar una Caja de Crédito y Ahorro Obrero con apoyo del Estado y aportes patronales, fundamentalmente destinada a ayudar a los trabajadores durante el período interzafra, cuando no tenían trabajo.

$\mathrm{Al}$ igual que con Bascary, los fracasos para imponer legislación social al área azucarera, fueron una constante. Sin embargo, en 1923 el gobernador presentó dos proyectos de ley para mejorar el nivel de vida de los obreros. Dispuesto a obtener la sanción a toda costa, los proyectos de Salario Mínimo y de jornada laboral de 8 horas se aprobaron de modo irregular en la Legislatura y generaron un conflicto que terminó en una de las huelgas más grandes de la historia de la provincia. Las fábricas paradas, la prensa culpando al gobernador de "hacer política obrerista con vías electorales" ${ }^{37}$, los industriales realizando un lockout que amenazaba con ahogar la economía provincial y el radicalismo desangrándose en discusiones internas, fueron el saldo de este intento de legislar derechos básicos para los trabajadores $^{38}$.

35 Cfr. María Lenis, "El proteccionismo en retirada. Las dificultades del Centro Azucarero Argentino (1912-1923)”, Población y Sociedad, 14-15, (2007-2008): 71-104.

36 María Celia Bravo, Campesinos, azúcar, 234.

37 La Gaceta, 02/06/1923.

38 El Diario, 01/06/1923, La Razón, 01/06/1923. 
Bajo presiones y contra el consejo de todo el entramado de alianzas que el gobernador había tejido en el mundo obrero, Vera retrocedió ${ }^{39}$ Lo hizo a cambio del pago de un paquete de impuestos que le permitiría sobrellevar las dificultades económicas de la provincia. Los empresarios pagaron, pero exigieron la "neutralidad" del Poder Ejecutivo Provincial respecto a la aplicación de las leyes laborales ${ }^{40}$.

La claudicación del gobierno demostró que no era sencillo reglamentar el trabajo en los espacios azucareros, ni que era unívoca la voluntad estatal de hacer cambios profundos en la estructura de beneficios del mundo obrero en los campos provinciales. La victoria empresaria les permitió a los industriales volver a apoyarse en la idea del carácter privado e individual de las relaciones laborales. "Los obreros son libres de cambiar de oficio, de vender su trabajo al mejor precio que obtengan [...] a su vez los patrones -empresarios, industriales, etc.- son libres de pagar a sus trabajadores los salarios que con ellos convengan o estipulen" 41 . Subyacía a sus discursos la idea de que los beneficios obtenidos por ley generarían desigualdad de condiciones entre las partes, "al derecho individual, al interés de cada uno corresponde, y no al poder del Estado, organizar y reglar las condiciones del trabajo, para que sus beneficios se compartan entre todos, con una igualdad que la ley no puede establecer sin violar el derecho de algunos otros" $"$.

39 Diario de Sesiones de la Cámara de Diputados, año 1923, Tucumán, Imprenta La Gaceta, 633. Citado por Daniel Santamaría, Movimientos Sociales. Las huelgas azucareras de Tucumán, 1923. Historia Testimonial Argentina. Documentos vivos de nuestro pasado, Buenos Aires: CEAL, , 1984), 30-31.

40 Revista Azucarera No 244, Año XX-2 $2^{a}$ Época, mayo de 1923.

41 El Salario Mínimo, Exposición del Centro Azucarero Nacional. Inconstitucionalidad de la ley. Fallo de la Corte Suprema de Estados Unidos”, Folleto editado por el Centro Azucarero Nacional (Buenos Aires: Ferrari Hnos., 1923), 3-16. Asimismo, sostenían que una medida de esa naturaleza igualaba a los trabajadores, ya que los más aptos y laboriosos resultaban equiparados con aquellos menos idóneos y "torpes". Este argumento no tenía en cuenta, o prefería no hacerlo, que el proyecto de ley sí establecía como criterios para fijar la remuneración, el tipo de tarea desarrollada y el grado de calificación, por lo tanto se desprendía que no todos los trabajadores empleados en las firmas azucareras percibirían los mismos ingresos.

42 El Salario Mínimo, Exposición del Centro Azucarero Nacional. Inconstitucionalidad de la ley. Fallo de la Corte Suprema de Estados Unidos", Folleto editado por el Centro Azucarero Nacional (Buenos Aires: Ferrari Hnos, 1923), 23. 
Con serias dificultades para legislar sobre jornada y salario en el mundo rural, el gobierno avanzó sobre otra área compleja, la salud. En ese sentido, los territorios de ingenio eran enclaves con altas tasas de mortandad, mortalidad infantil y enfermedades contagiosas ${ }^{43}$. Incluso desde el Departamento Nacional de Higiene se llamaba la atención por "el extraordinario desarrollo" del paludismo en las zonas de producción azucarera? que provocaba un crecimiento vegetativo mínimo ${ }^{44}$. Preocupados por los datos y las epidemias, los legisladores, luego de varios intentos fallidos, pusieron a la asistencia médica en los ingenios en la agenda política ${ }^{45}$. Convertida en Ley Provincial $N^{\circ} 1.366$, se estableció la obligación de los establecimientos industriales con más de 200 empleados de prestar asistencia médica permanente y gratuita a sus trabajadores ${ }^{46}$.

A pesar de los esfuerzos estatales, ni los trabajadores ni los industriales estuvieron de acuerdo con la ley. Los primeros la consideraban insuficiente y la denunciaban como un esfuerzo estatal por curar con "jarabe de palo". Aspiraban a reglamentaciones que tuvieran como fin impedir la explotación que, señalaban, era la causa real de la enfermedad ${ }^{47}$.Los industriales, por su parte, interpretaron las exigencias estipuladas como un ataque violento, e incluso afirmaron que la ley llevaría al quebranto de

43 Alfredo Bolsi y Patricia D’Arterio, Población y azúcar en el noroeste argentino. Mortalidad infantil y transición demográfica durante el siglo XX (Tucumán: dUNT, 2001),17; Alfredo Bolsi y Patricia D’Arterio, Población y complejo azucarero en Tucumán durante el siglo XX (Tucumán Instituto de Estudios Geográficos: 1999), 22.

44 Diego Armus y Susana Belmartino, "Enfermedades, médicos y cultura higiénica", en Historia Argentina. Crisis económica, avance del Estado e incertidumbre política (1930-1943), t. VII dir. Alejandro Cattaruzza, (Buenos Aires: Sudamericana, 2001), 290.

45 Diario de Sesiones de la Cámara de Diputados de la Provincia de Tucumán, 7 de mayo de 1925; La Gaceta, 08/05/1925. Alejandra Landaburu, Los empresarios; 28; Florencia Gutiérrez y Gustavo Rubinstein, "La salud de los trabajadores en los ingenios azucareros: ¿responsabilidad empresarial o deber estatal? Tucumán durante el primer peronismo", en Actas de las VIII Jornadas La Generación del Centenario y su proyección en el NOA 1900-1950 (Tucumán, 2009): 13

46 La ley exigía también la entrega de leche a enfermos y a niños menores de tres años. En el plano de la prevención tenían la obligación de organizar conferencias sobre higiene y profilaxis y llevar un registro de las consultas para construir bases estadísticas. Diario de Sesiones de la Cámara de Diputados de la Provincia de Tucumán, 7 de mayo de 1925. Ministerio del Interior, Caja 41, Archivo de la Legislatura de Tucumán, 1926. Decreto del gobernador del 20 de marzo de 1926.

47 La Protesta, 06/05/1925. 
la industria ${ }^{48}$. Pero lo que más irritaba a los azucareros era nuevamente la injerencia estatal sobre sus espacios. Así, a través de su revista institucional, notas presentadas y entrevistas a la prensa, los dirigentes azucareros exclamaban que era deber del Estado y no del capital privado garantizar la salud de la población rural, dejando en claro que no cumplirían la ley. En esa dirección, los métodos usados por los empresarios y sus representantes, además de estos alegatos, para evitar la regulación estatal cubrían un abanico amplio de situaciones, desde recursos de inconstitucionalidad, amparos judiciales que impedían el cobro de multas o también la desobediencia lisa y llana. Pero fundamentalmente, se abocaron a naturalizar las prácticas sostenidas por años, caracterizándolas como algo que correspondía al "medio"49.

Esa idea de "el medio" como algo con reglas propias e inamovibles era el bastión de la defensa empresaria, pero también se refería a usos y costumbres vinculados al mundo rural de la provincia, que eran muy complejas de transformar. En esa dirección, la construcción de las políticas sociales fue un proceso complejo y no lineal que fue adquiriendo forma a partir de negociaciones y luchas entre el Estado y ese universo rural dirigido por las empresas. En la provincia de Tucumán, signada por el mundo azucarero, la ampliación de derechos debió atravesar la voluntad de un empresariado muy consciente de su poder.

En 1929 y 1940 los gobernadores volvieron a regular el salario mínimo con igual suerte que en 1919 y 1923. En 1929 el gobernador radical José Sortheix lanzó una iniciativa que retomaba las leyes obreras sancionadas bajo la gestión de $\operatorname{Vera}^{50}$. A diferencia del proyecto anterior, contemplaba seriamente la cuestión de las penalidades y multas ${ }^{51}$. Este nuevo intento del estado provincial de avanzar en la institucionalización de leyes sociales en el campo y establecer de manera más precisa las agencias que tendrían a cargo la fiscalización del cumplimiento efectivo de las leyes también pretendía dar observancia efectiva al Laudo Alvear, cuyo criterio distributivo

48 Daniel Santamaría, Azúcar y Sociedad en el Noroeste argentino (Buenos Aires: IDES, 1986): 75.

$49 \quad$ El Orden, 14 de abril de 1919.

50 Honorable Cámara de Diputados de la Provincia de Tucumán, 5 de junio de 1929, 78-79.

51 Revista La Industria Azucarera, $\mathrm{N}^{\circ}$ 428, junio de 1929, 430. 
obligaba a las patronales a garantizar a los trabajadores un salario digno. Sin embargo, a pesar de sus avales, la ley generó una contraofensiva patronal, capitaneada por los industriales azucareros y finalmente fue declarada inconstitucional ${ }^{52}$.

\section{LOS AÑOS TREINTA Y LA APARICIÓN DE LOS TRABAJADORES}

La familiaridad con una situación problemática muchas veces termina por invisibilizarla. En este sentido, la costumbre de convivir con un mundo rural ajeno a la legislación laboral transformó esta situación en una pintura natural para gran parte de la sociedad. E incluso algunos trabajadores consideraban los problemas de salud como una "fatalidad inexorable" 53 . Sin embargo, a mediados de los años treinta las denuncias obreras, las publicaciones de la prensa y las cartas de los trabajadores, así como también los debates parlamentarios que comenzaron a darse en Buenos Aires sobre las condiciones de trabajo en la industria azucarera, empezaron a visibilizar las dificultades de un estado provincial para dar respuestas a las demandas obreras. Frente a ellos, la constante reacción defensiva de los industriales mostró con mucha contundencia su voluntad de amurallamiento frente al avance del Estado que parecía inexorable, las falencias de los sistemas legales de protección social y los mecanismos políticos implementados por las industrias para evadir las normativas vigentes.

La literatura coincide en señalar que a partir de los años treinta se aceleró el proceso de construcción de un Estado orientado a dar soluciones en materia social. No solo por la ampliación de la estructura técnico-burocrática, sino que también la dinamización del mundo del trabajo, el crecimiento de

52 La apelación a la inconstitucionalidad de las leyes de salario mínimo era un mecanismo frecuente de defensa corporativa empresarial. La jurisprudencia del caso databa de 1929 cuando la Corte Suprema de Justicia de la Nación declaró inconstitucionales dos leyes de salario mínimo de la provincia de Mendoza, fallo que la Revista Azucarera publicó íntegro y que hizo extensiva la inconstitucionalidad a las primeras leyes sobre la materia sancionadas en Tucumán en 1923. El argumento señalaba que al tratarse de una locación de servicios por pagarse un "precio" por tonelada (precio por servicio) se trataba de una relación contractual entre partes cuya regulación se encuadraba dentro del Código Civil. De modo que solo el Congreso de la Nación poseía facultades para modificar las disposiciones de dicho Código y no a las Legislaturas provinciales.

53 Dora Barrancos, "Socialismo, higiene y profilaxis social, 1900-1930", en Política, médicos y enfermedades, comp. Mirta Lobato (Buenos Aires: Biblos, 1996), 117-149. 
las ciudades y el desarrollo de nuevas demandas, que impulsaron al Estado a dar respuestas más precisas sobre las necesidades de la población ${ }^{54}$. Pero ese bienestar asociado al trabajo estaba en constante desencuentro con el universo azucarero y rural tucumano. Frente a ello, y a modo de refuerzo, la propaganda industrial sobre los beneficios sociales y su obra de asistencia se multiplicaron. Llenaron las páginas de los diarios locales y nacionales con grandes recuadros y fotos del trabajo social y asistencial en las fábricas. De alguna manera los empresarios querían dejar sentada la redundancia de la intervención estatal en las poblaciones vinculadas al trabajo azucarero. También desde su órgano de prensa, sostenían una insistente campaña por demostrar su obra benefactora.

"Más de una vez se ha asegurado que las iniciativas de mejoramiento de las clases obreras [...] han correspondido siempre a gobiernos "obreristas" [...] la obra existente es ya vasta en este sentido y ella corresponde en gran parte a la propia industria que ha ido acumulando mejoras en la vida del obrero[...] que disfruta de los salarios más elevados que se pagan en las faenas agrícolas del país; que cuenta con habitación material [...]que ellos pagan la enseñanza que se imparte en las escuelas de las poblaciones respectivas; que las fábricas prestan servicios hospitalarios, que existen salas de espectáculos, campos de deporte, cines, bandas de música [...] todo ha sido creado y organizado en beneficio de

54 Anahí Ballent, "Ingeniería y Estado: la red nacional de caminos y las obras públicas en la Argentina, 1930-1943”, História, Ciências, Saúde-Manguinhos, 15 3, (2008): 827-847; María Silvia Di Liscia, "Dificultades y desvelos de un estado interventor. Instituciones, salud y sociedad en el interior argentino. La Pampa, 1930-1946”, Anuario IEHS, 22, (2007): 93-123; María José Ortiz Bergia, De caridades y derechos. La construcción de políticas sociales en el interior argentino. Córdoba (1930-1943) (Córdoba: CEH, 2009) todo obra; María José Ortiz Bergia, "El intervencionismo estatal en el espacio provincial. Construcción de políticas laborales en Córdoba, 1930-1943. Población \& Sociedad, Revista de Estudios Regionales, 16 (2009): 151-186; Carolina Biernat y Karina Ramacciotti, Preguntas y herramientas para el análisis de las políticas sociales", en Políticas sociales, entre demandas y resistencias. Argentina 1930-1970, ed Carolina Biernat y Karina Ramacciotti (Buenos Aires: Biblos, 2012): 9-36; Hernán González Bollo, José Francisco Figuerola: "De funcionario del estado interventor conservador a experto de la coalición peronista (1930-44)", en Primer Congreso de Estudios sobre el Peronismo: la primera década (Universidad Nacional de Mar del Plata. Mar del Plata, 2008), historiapolitica.com/datos/biblioteca/gbollo2.pdf; Ricardo Gaudio y Jorge Pilone, "Estado y relaciones laborales en el período previo al surgimiento del peronismo, 1935-1943", en Desarrollo Económico, vol. 24, N 94, (1984): 235-273 Alejandra Landaburu, Empresarios, 29. 
la población obrera y sin leyes que lo establezcan... todo por un sentimiento de humanidad y de justicia social ${ }^{55}$.

En 1943, asimismo, editaron un libro con estadísticas y datos sobre el trabajo realizado en cada uno de los ingenios durante la primera mitad del siglo XX. Allí se podía ver que algunos de los 27 ingenios tucumanos tenían regímenes que seguridad social muy modernos para la época. En varios de ellos había un hospital que? garantizaba la atención gratuita de los trabajadores, mientras que otros tenían a sus trabajadores asegurados contra riesgos del trabajo. ${ }^{56} \mathrm{El}$ Ingenio Concepción brindaba además, una casa a las viudas de los obreros que fallecían durante un accidente laboral, mientras que el ingenio Mercedes les otorgaba una pensión y el Bella Vista les daba un año de sueldo. Por su parte, el Amalia otorgaba un salario familiar a sus trabajadores. ${ }^{57}$ Sin embargo, estas situaciones no eran la norma y la precariedad de las condiciones de vida y de trabajo de las zonas azucareras quedaba reflejada con una contundente frecuencia anual, en los rechazos para el servicio militar por baja talla, peso o secuelas de enfermedades que en la campaña llegaban casi al $70 \%{ }^{58}$.

Asentados en la lógica de brindar beneficios para evitar la injerencia estatal, algunos ingenios fueron ampliando sus áreas de cobertura social, mientras que otros se convirtieron en bastiones de resistencia. Las estadísticas vitales, no obstante, preocupaban. El problema, según denunciaban los trabajadores, se centraba en la falta de sanciones o en "el perdón hecho sistemático en el Departamento Provincial de Trabajo" 59 . Martín

55 La Industria Azucarera, No 499, mayo de 1935, citado por Landaburu, Los empresarios, 239.

56 El ingenio Bella Vista, el San Pablo y el Santa Ana tenían hospital. En algunos ingenios el médico acudía solo dos veces por semana y en casos de gravedad, el enfermo era trasladado a la capital. Tal era el caso de los ingenios Esperanza, Santa Lucía y Concepción. Pero en la mayoría la asistencia a los enfermos no era cubierta por la empresa. Juan Bialet Masse, Informe sobre el estado de la clase obrera (Madrid Hyspamérica: 1985); Olga Paterlini de Koch, Los pueblos azucareros de Tucumán (Tucumán: Editorial del Instituto Argentino de Investigaciones de Historia de la Arquitectura y del Urbanismo, 1987); Alejandra Landaburu, "Los empresarios azucareros, la tesis habla de eso.

57 Alejandra Landaburu, "Los empresarios", Centro Azucarero Argentino, Asistencia social en la industria azucarera, ed Emilio Schleh (Buenos Aires: Establecimiento Gráfico Ferrari Hermanos, 1943).

58 Alfredo Palacios, El dolor, 94.

59 Nota enviada por la Sociedad de Empleados y Obreros del Comercio al Ministro de Gobierno Dr. Norberto Antoni, reproducida en La Gaceta, 25/03/1936. 
Manso, director del DPT durante la gestión de Campero, comentaba en las memorias de esa oficina que "Los obreros sólo quieren ver en el Departamento del Trabajo lo que su creación implica, o sea la consagración de los derechos que les acuerdan las leyes sociales, y una garantía - de parte del Gobierno- en la defensa de sus intereses. Con este sazonado criterio, exigen soluciones inmediatas, sin reparar si al caso lo tutelan claramente las leyes, o si el Departamento tiene atribuciones para exigir al patrón el acatamiento de sus resoluciones" ${ }^{\prime 60}$. Por otro lado, las memorias del DPT comenzaban a expresar que sus funciones se habían "extendido y complicado" "Y Y que esto se complejizaba aún más en épocas de zafra, cuando la labor se multiplicaba. El propio Departamento señalaba que muchas veces, por la falta de personal, debían dejar a cargo de la policía el control del cumplimiento de la legislación social en las zonas azucareras. Pero estas falencias también se sumaban a la cantidad de denuncias de condonación de deudas y "sospechas de afinidad política" realizadas por los obreros y por la misma Legislatura provincial, que impedían el correcto accionar de la repartición ${ }^{62}$. El DPT, por su parte, defendía el incumplimiento de normas, como la prohibición de proveedurías, señalando que el Estado forzosamente debía "tolerar ese problema de aparente transgresión legal", ya que en el fondo la práctica del endeudamiento no constituía "sino la intención de proporcionar elementos indispensables para el trabajador" y la práctica estaba tan arraigada que su extinción era compleja ${ }^{63}$.

En definitiva, el Estado solo pudo generar un marco legal y otorgar un espacio de negociación, pero no logró nunca garantizar el cumplimiento de

60 "Memorias del Departamento Provincial de Trabajo", Tucumán, enero de 1936 y Memoria del Departamento Provincial de Trabajo", Tucumán, enero de 1937.

61 "Memorias del Departamento Provincial de Trabajo", Tucumán, enero de 1936; Anuarios Estadísticos de la Provincia de Tucumán, 1925-1943, y Censo Industrial 1935, Buenos Aires: Talleres de la S.A. Casa Jacobo Peuser Ltda., 1938. De esto también daba cuenta la creciente extensión de las Memorias del DPT que registró año a año un incremento considerable en el número de páginas y en la información brindada sobre las tareas de la repartición. De esta forma, mientras que las memorias del año 1933 solo tenían cuatro páginas, las del año 1941 llegaron a 25 páginas.

62 Diario de Sesiones de la Honorable Cámara de Diputados de la provincia de Tucumán, año 1939, 133. En las memorias del DPT se desestiman denuncias de violación de la ley 11.278 de pago en moneda nacional llegadas de la campaña. "Se desestimaron por estar viciadas de nulidad y haberse errado el procedimiento, en unas y en otras, por la manifiesta mala fe con que fueron levantadas". "Memoria del Departamento Provincial de Trabajo", Tucumán, enero de 1936.

"Memoria del Departamento Provincial de Trabajo", Tucumán, enero de 1936. 
las normas y convivió (conflictivamente) con un statu quo, formas de hacer muy arraigadas y muy defendidas en el campo tucumano. Como señala Ernesto Bohoslavsky, existió una intención de diagramar y contener a la sociedad, pero que de esa voluntad política se hayan desprendido "aparatos estatales eficaces y correctamente financiados, es harina de otro costal"

A fines de los años treinta y ante los reiterados incumplimientos, el discurso estatal fue buscando argumentos que permitieran negociar algún tipo de espacio de control y desde el Estado se trabajó sobre la idea de que el bienestar que los industriales debían garantizarle a los trabajadores era "una exigencia que no descarta la preocupación gubernativa, sino que la complementa y la secunda" "Es. Esta mirada quedó plasmada en el primer congreso de Asistencia Social y Estadística Vital de la Provincia que se realizó en 1942 y del que participaron industriales, Iglesia y Estado. Allí el Ministro de Gobierno se apoyó en la tesis empresaria afirmando que la función del Estado era garantizar el bienestar de la población, pero acotó que esta tarea "debe ser coadyuvada por la acción privada". En ese sentido, en el marco de esta reunión los problemas del bienestar del trabajo rural fueron una oportunidad para desarrollar y discutir políticas públicas que permitieran también reacomodar la relación entre Estado, capital y trabajo. Así, demandó una política social integral entre lo público y lo privado destacando la necesidad de obtener la colaboración de los industriales azucareros, quienes "tienen la misión exclusiva de dotar a sus expensas de las comodidades más elementales que todo ser humano tiene derecho, máxime cuando él contribuye con su esfuerzo mediante su trabajo al engrandecimiento económico de aquellos" $"$.

Este giro en el discurso comenzó a colocar al trabajador en el centro de la discusión y a convertirlo en un "valor productivo", cuyo bienestar es-

64 Ernesto Bohoslavsky, "La incurable desidia y la ciega imprevisión argentinas. Notas sobre el Estado, 1880-1930”, en Estado y política en la Argentina actual, comp. por Carlos Vilas, Osvaldo Iazzetta, Karina Forcinito y Ernesto Bohoslavsky (Buenos Aires: Universidad Nacional de General Sarmiento/Prometeo, 2005) 113.

65 La Gaceta, Tucumán, 01/09/1938.

66 La Unión, Tucumán, 21/09/1942. 
taba vinculado al desarrollo de la región ${ }^{67}$. En esa línea, la cuestión de los salarios no era menor y nuevamente en 1940, como lo fue en 1919, 1923 y 1929, el gobierno intentó volver a legislar sobre salario mínimo. En ese momento los reclamos obreros habían venido incrementándose al punto de extender el debate hacia un campo más amplio de problemas que ponían cotidianamente sobre el tapete, a través de las páginas de la prensa, las pésimas condiciones de vida de los trabajadores azucareros. Habían pasado doce años del laudo presidencial que garantizaba $\$ 3$ por tonelada de caña cosechada y los jornales no estaban ni cerca de esas cifras. A principios de los años cuarenta rondaban un promedio de $\$ 73$, mientras que el Departamento Provincial de Trabajo había determinado que se necesitaban $\$ 213$, casi tres veces más, para mantener un hogar de cinco miembros ${ }^{68}$.

A los industriales les resultaba mucho más fácil explicar la desidia del trabajador de la campaña, que garantizar el pago acordado. La prensa corporativa había afirmado siempre que el obrero azucarero "no conoce los pasatiempos saludables" "69, o que tiene "un conformismo superlativo [...] al grado de no oírsele si quiera mencionar el deseo de mejorar su situación"70. Estas ideas estaban tan arraigadas que incluso investigadores de la Universidad de Tucumán destacaban que "la indolencia" era la característica del poblador de la campaña, por ello "de nada servirá que el obrero tenga mejor salario si le ha de emplear, como hasta ahora, para alcoholizarse" 71 . En esas representaciones extendidas en la provincia encontraban justificación los vales, el maltrato, el incumplimiento legal, las proveedurías, los bajos salarios y la inacción en materia de salud.

La cultura del territorio azucarero daba a sus habitantes un marco de sentido a partir del cual se desarrollaban sus experiencias. La discusión de esas lógicas tan internalizadas promovió cambios en los procesos de demanda,

67 Emilio Tenti Fanfani, Estado y pobreza: estrategias típicas de intervención (Buenos Aires: CEAL, 1989), 62; Eric Carter, "Malaria, Landscape, and Society in Northwest Argentina in the Early Twentieth Century.," Journal of Latin American Geography. Vol. 7, No. 1, (2008): 7-38.

68 Departamento Provincial de Trabajo, Memoria, Documento mimeografiado, 1942.

69 Revista Azucarera, mayo de 1922, 132.

70 Revista Azucarera, mayo de 1910, 71-88.

71 Miguel Figueroa Román, Problemas, 148. 
organización y lucha obrera que paulatinamente ampliaron los márgenes de la discusión por el bienestar, pero no logró transformar las prácticas. A pesar de las representaciones negativas, las dificultades y los fracasos, las leyes, las políticas sociales y los esfuerzos estatales movilizaron recursos en la sociedad y generaron expectativas de cambio que poco a poco fueron cuajando también en sus propios beneficiarios. Un conjunto separado de leyes no constituyen una política, pero cada una de ellas articula imaginarios sociales vinculados a derechos obtenidos y funcionan como cristalización de las luchas que se desarrollan en el campo social. Así, las acciones del Estado no habían logrado garantizar el desarrollo de espacios laborales con derechos obtenidos, pero sí habían generado mecanismos de reconocimiento entre los trabajadores a partir de los efectos de las significaciones y las normas institucionalizadas sobre las posiciones relativas de los actores sociales del espacio azucarero.

Parte de ese proceso cuajó en 1936, cuando se conformó en Tucumán el primer sindicato con proyección que tuvo la actividad, la Unión General de Trabajadores de la Industria Azucarera (UGTIA). Poco tiempo después de fundada, la organización publicó en su órgano de prensa la carta de un obrero del Ingenio Concepción. Allí el trabajador contaba los pormenores de lo acontecido durante un almuerzo ofrecido por el ingenio a los participantes de un congreso de abogados:

"Nos repusieron las prendas que teníamos de peor uso, hasta dejarnos de buena presentación [...] Después se le metió en la cabeza que habíamos de lavarnos la cara y las manos con jabón, luego [...] nos llevó a la peluquería, donde nos pusieron hasta agua de olor. El día del almuerzo [...] nos presentamos nosotros. Ellos nos preguntaban sobre lo que trabajábamos, cuánto nos pagaban, cómo era el trabajo que nos daban, y nosotros dele contestar a todos, tal como nos habían estado diciendo toda la noche antes, teniendo mucho cuidado con equivocarse, que esto también nos lo habían dicho. Cinco pesos diarios por seis horas de trabajo, casa muy buena, muy buen trato en el trabajo y en la casa, pago puntual sin descuento. Decíamos nosotros a los que nos preguntaban. Algunos dijeron que querían ver la casa que 
nos daba el ingenio; los llevé, diciendo que era la mía, el chalet del jefe de máquinas, cosa que también me habían dicho"72.

La carta y su contexto visibilizaban muy claramente las tensiones con las que convivía la industria azucarera en la provincia. Por los compromisos políticos y económicos, los ingenios eran espacios frecuentemente visitados por personalidades y huéspedes distinguidos de la provincia. Frente a ellos, las apariencias sobre la calidad de vida de los trabajadores eran, sin duda, un asunto de crucial importancia. Sostenidas por una política arancelaria que encarecía el precio del azúcar en el mercado interno y discutidas por amplios sectores de la sociedad, estas empresas eran muy sensibles a los comentarios de los observadores externos y de los "visitantes ilustres" que solían recibir. Para ello, frecuentemente disimulaban las verdaderas condiciones de vida y trabajo de sus obreros a través de prácticas de enmascaramiento. Sin embargo, la realidad denunciada por los trabajadores era otra muy distinta. En efecto, la carta terminaba relatando que entre los visitantes estaban el obispo y el gobernador y "Se veía bien a las claras que no creían una palabra de todas las nuestras [...] Todos allá bien sabían que trabajamos más que las mulas de los carros y nos tratan mucho peor, que reventamos de miseria y de hambre, que estamos amontonados con nuestras familias como los chanchos en los casuchines que nos proporcionan" 73 .

Había, quizás, una brecha muy grande entre los discursos estatales y las prácticas reales, pero su intervención fue construyendo una idea de orden social y político diferente a aquel caracterizado por la explotación, el maltrato en los lugares de trabajo, la violencia y la represión. Por ello, señala Tulio Halperin Donghi que "cuando ese dispensador de tantos males que era el Estado pareció mostrar de pronto un rostro más benévolo" nada tenía de extraño que las prevenciones obreras se atenuaran rápidamente ${ }^{74}$.

Al compás de un Estado que buscaba espacios de negociación con el mun-

72 "Carta de un obrero del ingenio Concepción", publicada en El Surco, Año 1, №1, Tucumán, octubre de $1936,5$.

73 "Carta de un obrero", 5.

74 Tulio Halperin Donghi, La democracia de masas, (Buenos Aires: Paidós, 1999$), 37$. 
do azucarero y un universo sindical que crecía en todo el país, los testimonios obreros empezaron a aparecer con más frecuencia en la prensa. Esto tuvo que ver con que esta se mostró más receptiva, pero también porque atrás de ellos había crecido la organización, tanto que entre 1935 y junio de 1943 se fundaron ocho sindicatos azucareros ${ }^{75}$. Cartas, reportajes, informes y editoriales, fueron rescatando la percepción obrera sobre sus condiciones de vida. Así, por ejemplo, un obrero de La Fronterita se extendió sobre las "vicisitudes económicas y morales" por las que atravesaban los trabajadores azucareros que tenían "la sensación de no tener ningún valor" 76 . Un trabajador del Ingenio La Corona se quejaba, "las casas que habitamos son inmundas" 77 . otros denunciaron baños "antihigiénicos" y "en estado ruinoso" que "atentaban contra la salud de la población obrera". Contaban que "La mayoría de nosotros ganamos un salario de 2,50 pesos y trabajamos cuatro días a la semana". ${ }^{78}$ En un manifiesto, asimismo, otro grupo señalaba "que no se pagan los accidentes de trabajo." 79 Por su parte, la UGTIA envió un memorial al gobernador informando que la asistencia médica era "una verdadera calamidad" la prensa extendieron sus denuncias visibilizando "la miseria en que vive nuestro pueblo" 81 .

La industria azucarera fue el motor de la economía tucumana y el mundo del trabajo construido a su alrededor fue siempre un espacio de intensos conflictos, tanto económicos como ideológicos y políticos entre Estado, empresarios y trabajadores. Los gobiernos provinciales habían batallado casi desde 1917 contra un número importante de industriales que, atrincherados en una suerte de desobediencia empresaria, desconocían la vigencia de normas y reglamentaciones laborales. Los intentos de hacerlas

75 María Ullivarri, Organizar la clase obrera. Sindicatos, resistencias y luchas en el mundo azucarero tucumano delaentreguerra,enTrabajoySociedad,24(2015), http://www.unse.edu.ar/trabajoysociedad $/ 24 \% 20$ Ulivarri $\% 20$ Maria $\% 20$ Organizar $\% 201 \mathrm{a} \% 20$ clase $\% 20$ obrera $\% 20$ sindicatos $\% 20$ azucarero.pdf

76 La Gaceta, Tucumán 17/08/1942.

77 La Gaceta, Tucumán, 28/04/1942. 
cumplir habían consolidado vínculos entre gobierno y trabajadores que fueron transformando las prácticas obreras y quebrando los patrones más consolidados de dominación. Los resultados no fueron inmediatos ni tampoco tangibles en términos de mejoras concretas. Sin embargo, no deben desdeñarse para la experiencia de los trabajadores azucareros las protestas que comenzaron a crecer, los reclamos públicos, los logros organizativos que tuvieron lugar en algunos ingenios.

\section{A MODO DE CIERRE}

Pensar las dinámicas y los modos de articulación entre las estructuras de gobierno, los agentes económicos y las demandas obreras del mundo rural tucumano, nos sirve para reflexionar acerca de las formas en las que el proceso de avance de la política social en espacios rurales se fue construyendo en el país, las formas en las que fue discutido el bienestar y el lugar que los actores involucrados tuvieron en ese proceso. Mucho más se ha escrito sobre el avance de políticas sociales en las áreas urbanas, y eso sirve para contrastar con crudeza las dificultades que ese proceso tuvo en estos universos culturales rurales o periurbanos, donde las lógicas del poder estaban tejidas de manera muy distinta. En Tucumán, 27 ingenios regían los tiempos de la campaña. Sostenidos políticamente por lazos de familia, vínculos económicos y fuerte representación corporativa, tanto en la provincia como en Buenos Aires, eran activos partícipes de la política. A partir de la llegada de gobiernos radicales las lógicas cambiaron y los esfuerzos estuvieron puestos en penetrar las infranqueables murallas de los espacios azucareros por un lado, y en frenar ese avance, por el otro. En esa clave, el Estado se concentró en intentar garantizar, primero la sanción de legislación laboral en territorios muy cerrados y luego, con menos énfasis, tratar de garantizar la aplicación. En ese sentido, el triunfo parecía estar más centrado en lograr la discusión de los beneficios que en velar por su cumplimiento. Frente a eso, el bienestar era disputado por las empresas quienes decían garantizar la "asistencia social" de sus trabajadores. En paralelo, sin embargo, repetían que el buen vivir de los trabajadores era una función inalienable del Estado, y solo correspondía al capital contribuir a él mediante los impuestos. Más cómodos estaban en el lugar de contribu- 
yentes, desde donde su posición como principales garantes del sustento financiero tucumano ampliaba su margen de maniobras.

Existe un cierto consenso respecto a que la consolidación de "lo social" como problema ha sido el producto de negociaciones y disputas entre la sociedad y el Estado. Los modelos de seguridad social siempre tienen un componente central: están construidos a partir de tensiones y pujas de intereses que moldean la forma en la que estos se desarrollan y que, en líneas generales, quizás por el tenor de los actores involucrados, difieren en los ámbitos urbanos y los rurales. En la provincia de Tucumán, la acción del Estado estuvo siempre muy condicionada por los intereses azucareros, cuyo rol protagónico en la historia provincial volvía dificultosa la tarea de legislar sobre sus prácticas y sobre las relaciones laborales que eran consideradas de índole privado. Y si bien la industria se había consolidado a la par de la intervención y regulación estatal, había sabido delimitarle al Estado muy bien las fronteras de lo posible.

Los intentos de garantizar derechos por la vía legislativa y la receptividad a demandas obreras, convirtieron a los gobiernos radicales en la principal amenaza de los azucareros. En esa dirección, la inmediata reacción de los industriales y sus posibilidades de acción corporativa y atrincheramiento judicial muestran con mucha contundencia los mecanismos políticos implementados por las industrias para evadir las normativas vigentes. Los inconvenientes en la aplicación de las normas abrieron la puerta para la intensificación de un debate acerca de los derechos sociales en el mundo rural y de las posibilidades de la subsidiariedad de las políticas sociales vinculadas al trabajo, que comenzaron a adquirir una forma más nítida durante los primeros años cuarenta.

Las respuestas a las preguntas sobre la naturaleza de las dificultades estatales para poder garantizar el cumplimiento de normativas en los ingenios son diversas. La capacidad reactiva y el poder de los industriales jugaban a su favor, pero también es cierto que el Estado no funcionaba como un conjunto aceitado de mecanismos, sino que estaba sujeto a infinitas limitaciones y cruzado por innumerables tensiones internas. La pobreza en recursos humanos y materiales fue la norma de los Estados provinciales, 
pero tampoco existió una voluntad unívoca para acceder a resultados satisfactorios, ya que al interior del mismo Estado convivía una diversidad de posturas, varias de las cuales estaban alineadas con la industria azucarera. En esa dirección, entendemos que la construcción de las políticas sociales no fue un proceso lineal, dirigido y prolijo, mucho menos en los espacios rurales, donde la resistencia doblegaba cualquier esfuerzo estatal. Muy por el contrario, fue una trayectoria conflictiva, surcada por disputas, negociaciones y por la voluntad de las partes, oferentes, beneficiarios y garantes que paulatinamente fueron ampliando los márgenes de la discusión por el bienestar.

\section{Bibliografía}

Alvear, Laudo. Biblioteca del Congreso de la Nación, serie 7, asuntos Económicos. Buenos Aires, 1965.

Armus, Diego y Susana Belmartino, "Enfermedades, médicos y cultura higiénica”. En Nueva Historia Argentina. Crisis económica, avance del Estado e incertidumbre política (1930-1943) t. VII, dirigido por Alejandro Cattaruzza, Buenos Aires: Sudamericana, 2001, 283-329.

Ascolani, Adrián. El sindicalismo rural argentino. Bernal: EdUNQui, 2009. Ballent, Anahí. "Ingeniería y Estado: la red nacional de caminos y las obras públicas en la Argentina, 1930-1943”. História, Ciências, Saúde-Manguinhos, 153 (2008): 827-847.

Barrancos, Dora “Socialismo, higiene y profilaxis social, 1900-1930" En Política, médicos y enfermedades,compilado por. Mirta Lobato. Buenos Aires: Biblos, 1996, 117-149.

Bialet Masse, Juan. Informe sobre el estado de la clase obrera. Madrid Hyspamérica: 1985.

Biernat, Carolina y Karina Ramacciotti, "Preguntas y herramientas para el análisis de las políticas sociales". En Políticas sociales entre demandas y resitencias. Argentina 1930-1970, editado por Carolina Biernat y Karina Romacciotti. Buenos Aires: Biblos, 2012.

Bohoslavsky, Ernesto. La incurable desidia y la ciega imprevisión argentinas. Notas sobre el Estado, 1880-193 en Estado y política en la Argentina actual. Editado por Carlos Vilas et al. Buenos Aires: UNG Sa/Prometeo Libros, 2005. 
Bolsi, Alfredo y Patricia D’Arterio, Población y complejo azucarero en Tucumán durante el siglo XX. Tucumán: Instituto de Estudios Geográficos UNT, (1999).

Bolsi, Alfredo y D’Arterio, Patricia. Población y azúcar en el noroeste argentino. Mortalidad infantil y transición demográfica durante el siglo XX. Tucumán:UNT, 2001.

Bravo, Augusto La industria azucarera en Tucumán. Sus problemas sociales y sanitarios. Tucumán: Imprenta Violetto, 1966.

Bravo, María Celia. Campesinos, azúcar y política. Cañeros, acción corporativa y vida política en Tucumán (1895-1930). Rosario: prohistoria, 2009.

Campi, Daniel. “ Coacción y Mercado del trabajo consideraciones en torno a Tucumán, Argentina , segunda mitad del siglo XIX”. En historia i projecte social, homenaje a Josep Fontana, editado por Franscesc Espinet Burunat (Barcelona: Crítica, 2004).

Campi, Daniel y Patricia Juárez Dape. "Despegue y auge azucarero en Perú y Argentina: semejanzas y contrastes” Illei i Imperi, 9 (2006).

Campi, Daniel. "Azúcar y trabajo. Coacción y mercado laboral en la Argentina, 1856-1896", (Tesis de Doctorado-Universidad Complutense de Madrid. Madrid, 2002)

Campi, Daniel. "Contrastes cotidianos. Los ingenios del norte argentino como complejos socioculturales, 1870-1930”. Varia Historia, vol. 25, $\mathrm{N}^{\circ 0} 41$ jan/jun (2009): 245-267.

Carter, Eric. "Malaria, Landscape, and Society in Northwest Argentina in the Early Twentieth Century". Journal of Latin American Geography.Vol. 7, No 1, (2008): 7-38.

Castel, Robert. La metamorfosis de la cuestión social. Una crónica del salariado. Buenos Aires: Paidós: 1997.

Centro Azucarero Argentino, Asistencia social en la industria azucarera, editado por Emilio Schleh. Buenos Aires: Establecimiento Gráfico Ferrari Hermanos, 1943.

Centurión Josefina. "Cultura y Sociedad en los pueblos Azucareros"( termina la licenciatura, Universidad Nacional de Tucumán, 2000).

Di Liscia, María Silvia. "Dificultades y desvelos de un Estado interventor. Instituciones, salud y sociedad en el interior argentino. La Pampa, 1930-1946”. Anuario IEHS, 22 (2007): 93-123. 
"El saliario minimo, exposición del cuento aguacero Nacional insconstitucionalidad de la ley. Fallo de la corte suprema de Estados Unidos”, folleto editado por el centro Azucarero Nacional. Buenos Aires: Ferrari Hnos., 1923

Figueroa Román, Miguel. "Problemas sociales de Tucumán”.: Revista Sustancia, enero-febrero, año IV, $\mathrm{N}^{\circ}$ 13. (1943).

Gaudio, Ricardo y Jorge Pilone, "Estado y relaciones laborales en el período previo al surgimiento del peronismo, 1935-1943”. Desarrollo Económico, vol. 24, Nº4, (1984).

Girbal, Noemí. "Azúcar, Poder Político y Propuestas de Concertación para el Noroeste argentino en los años veinte. Las conferencias de gobernadores de 1926-1927”. Desarrollo Económico,Vol. 34, No 133, (1994): 107-122.

Golbert, Laura. "Notas sobre la situación de la historiografía sobre la política social en Argentina”. En El país del no me acuerdo. (Des)memoria institucional e historia de la política social en la Argentina, compilado por Julián Bertranou, Juan Manuel Palacio y Gerardo Serrano Buenos Aires: Prometeo, 2004, 25-32.

González Bollo, Hernán, y José Francisco Figuerola: “De funcionario del estado interventor conservador a experto de la coalición peronista (1930-44)". En Primer Congreso de Estudios sobre el Peronismo: la primera década. Universidad Nacional de Mar del Plata. Mar del Plata (2008). historiapolitica.com/datos/biblioteca/gbollo2.pdf

Gutiérrez, Florencia y Gustavo Rubinstein, , La salud de los trabajadores en los ingenios azucareros: ¿responsabilidad empresarial o deber estatal? Tucumán durante el primer peronismo. En Actas de las VIII Jornadas La Generación del Centenario y su proyección en el NOA 1900-1950. Tucumán: Editorial, 2009.

Guy, Donna, Política azucarera argentina. Tucumán y la Generación del ochenta, Tucumán, Tucumán: EDUNT, 2010.

Hale, Charles. Resistance and Contradiction Miskity Indians and the Nicaraguan State, 1894-1987. California: Stanford University Press, 1994. Halperin Donghi, Tulio. La democracia de masas. Buenos Aires: Paidós, 1999.

Halperin Donghi, Tulio. Vida y muerte de la República Verdadera (19101930). Buenos Aires:Ariel, 2005. 
Landaburu, Alejandra. "Los industriales y el Departamento Provincial del Trabajo ante el conflicto obrero de 1919 en Tucumán”. En La sociedad del trabajo, Las instituciones laborales en la Argentina (19001955), compilado por Mirta Lobato y Juan Suriano. Buenos Aires: EDHASA, 2014.

Landaburu, Alejandra. "El empresariado azucarero tucumano frente a la política laboral del radicalismo. La ley de Salario Mínimo de 1923. En: Actas de las XXI Jornadas de Historia Económica. Caseros: Editorial 2008.

Landaburu, Alejandra. "Los empresarios azucareros y la cuestión social. Tucumán 1916-1930”, (Tesis de Doctorado Universidad Nacional de Tucumán, Tucumán, 2014).

Leite Lópes, José Sergio. El Vapor del Diablo. El trabajo de los obreros del azúcar. Buenos Aires: Antropofagia. Colección de Estudios de Antropología del Trabajo (2011).

Lenis, María. Empresarios azucareros y cuestión social. El Centro Azucarero Argentino frente a las huelgas de 1923. En Actas de las VIII Jornadas La Generación del Centenario y su proyección en el NOA, 1900-1950. Tucumán: editorial 2009

Lenis, María, "El proteccionismo en retirada. Las dificultades del Centro Azucarero Argentino (1912-1923)”, Población y Sociedad, 14-15, (2007-2008), 71-104.

Lenis, María. "La política editorial del Centro Azucarero Argentino, 18941923". En Actas del III Seminario de História do Acucar. Sao Paulo: USP, 2010.

Lvovich, Daniel y Juan Suriano (eds). Las políticas sociales en perspectiva histórica. Buenos Aires: Prometeo, 2006.

Moyano, Daniel desde la empresa.Buenos Aires Prometeo, 2015

Moyano, Daniel "Empresas azucareras, tecnología y actividad matelurgica en Tucumán en la primera mitad del siglo XX” actas de las II Jornadas de Jovenes Investigadores,UNT-AUGM.Vol No (2008):

Ortiz Bergia, María José De caridades y derechos. La construcción de políticas sociales en el interior argentino. Córdoba (1930-1943) Córdo290 ba: CEH, 2009.

Ortiz Bergia, María José. "El intervencionismo estatal en el espacio provincial. Construcción de políticas laborales en Córdoba, 1930-1943”. 
Población \& Sociedad, Revista de Estudios Regionales, 16 (2009): 151-186.

Palacios, Alfredo. El dolor argentino, Buenos Aires: Claridad, 1938.

Paterlini De Koch, Olga. Los pueblos azucareros de Tucumán. Tucumán: Editorial del Instituto Argentino de Investigaciones de Historia de la Arquitectura y del Urbanismo, 1987.

Santamaría Daniel. Movimientos sociales. Las huelgas azucareras de Tucumán, 1923. Historia testimonial. Argentina. Documentos vivos de nuestro pasado. Buenos Aires: CEAL, 1984.

Sánchez Román, José. La dulce crisis. Estado, empresarios e industria azucarera en Tucumán (1853-1914). Sevilla/Madrid: Universidad de Sevilla-Consejo de Investigaciones Científicas, 2005.

Santamaría, Daniel. Azúcar y Sociedad en el Noroeste argentino. Buenos Aires: IDES, 1986.

Santos Lepera, Lucía. "La acción Católica tucumana, sociabilidad y cultura religiosa en los años treinta. El caso del teatro de hombre de San Pablo", No (2008).

Schleh, Emilio. La industria azucarera en su primer centenario. Buenos Aires: Ferrari Hnos, 1921.

Scott, James. Los dominados y el arte de la resistencia. Discursos ocultos. México: Era, 2000.

Tenti Fanfani, Emilio. Estado y pobreza: estrategias típicas de intervención. Buenos Aires: CEAL,1989.

Ullivarri, María. Organizar la clase obrera. Sindicatos, resistencias y luchas en el mundo azucarero tucumano de la entreguerra. En Trabajo y Sociedad, 24 (2015) http:/ / www.unse.edu.ar/trabajoysociedad/24\%20 Ulivarri $\% 20$ Maria $\% 20$ Organizar $\% 201 \mathrm{a} \% 20$ clase $\% 20$ obrera $\% 20$ sindicatos $\% 20$ azucarero.pdf

\section{Periodícos}

-El Diario, Buenos Aires

-La Gaceta, Tucumán

-El Orden, Tucumán,

-La Protesta, Buenos Aires

-La Razón, Buenos Aires

-Tierra Libre, Tucumán

-La Unión, Tucumán, 


\section{Documentos}

- Diario de sesiones de la Cámara de diputados de Tucumán. Período Legislativo de 1918-1919.

- Diario de sesiones de la Cámara de senadores de la Nación, 1937

- Diario de sesiones de la Honorable legislatura de la provincia de Tucuman, 1933

- La Industria Azucarera No 428, junio de 1924.

- Revista Azucarera 1910, 1913, 1922, 1923.

Para citar este artículo: Fernández de Ullivari, María. "Disputas en torno a las políticas públicas, la legislación laboral y el bienestar obrero en la 292 industria azucarera de Tucumán/Argentina (1917-1943)", Historia Caribe Vol. XII No. 31 (Julio-Diciembre 2017): 259-292. DOI: http://dx.doi. org/10.15648/hc.31.2017.9 